\title{
CARACTERÍSTICAS DA GOVERNANÇA CORPORATIVA E FATORES DETERMINANTES NAS MAIORES EMPRESAS ABERTAS DO BRASIL
}

\section{CORPORATE GOVERNANCE CHARACTERISTICS AND DETERMINANT FACTORS IN THE LARGEST BRAZILIAN PUBLIC COMPANIES}

\section{RESUMO}

O estudo buscou caracterizar a governança corporativa nas maiores empresas de capital aberto do Brasil, identificando seus possíveis fatores determinantes e o relacionamento desses fatores com as quatro dimensões representativas da qualidade da governança corporativa nesta pesquisa. Assim, analisaram-se dados de 81 empresas não financeiras, alusivos ao exercício contábil de 2015. Para mensurar a governança, 12 aspectos foram verificados em relatórios financeiros, formulários de referência e no website institucional das empresas. Na análise recorreu-se à estatística descritiva, regressão linear múltipla e correlação de Spearman. Os resultados mostraram que a qualidade da governança corporativa pode ser considerada apenas boa, tratando-se de firmas economicamente destacadas. Apenas a listagem nos segmentos diferenciados da B3, influencia a governança. Observou-se, todavia, que os aspectos: listagem em níveis diferenciados da B3, emissão de ADR, endividamento, tamanho e valor podem ajudar a explicar a qualidade da governança das firmas nas quatro dimensões constituintes da métrica adotada na pesquisa.

Palavras-chave: Governança Corporativa. Qualidade da Gestão. Mecanismos de Governança.

\begin{abstract}
This study aims to characterize the corporate governance in the largest Brazilian public companies, identifying its possible determinant factors and the relationship of these factors with four dimensions that represents corporate governance quality. Thus, we analyzed data from 81 non-financial firms to the 2015 period. The corporate governance was measured by 12 aspects, which were collected in financial reports, reference forms and corporate website. We used descriptive statistics, multiple linear regression and Spearman correlation for data analysis. The results show that corporate governance quality can be considered just good, since we are investigating firms economically representative. Further, only the presence in B3 governance segments has influence in corporate governance. However, we observed that the aspects of listing at B3 governance levels, ADR emission, debt, size and firm value can help to explain firms' corporate governance quality considering the four different dimensions that composes the metric used in this research.
\end{abstract}

Keywords: Corporate Governance. Management Quality. Governance Mechanisms.

\begin{abstract}
José Glauber Cavalcante dos Santos
Doutorando em Administração e Controladoria pela Universidade Federal do Ceará (UFC); Mestre em Administração e Controladoria pela UFC; Graduado em Ciências Contábeis pela UFC; Contato: Avenida da Universidade, 2431, Benfica, Fortaleza, CE, CEP: 60.020-180. E-mail: jglauber_cont@hotmail.com

\section{Tatiana Aquino Almeida}

Doutoranda em Administração e Controladoria pela Universidade Federal do Ceará (UFC); Mestre em Administração e Controladoria pela UFC; Graduada em Ciências Contábeis pela UFC; Contato: Avenida da Universidade, 2431, Benfica, Fortaleza, CE, CEP: 60.020-180. E-mail: tatianaaquino.ufc@gmail.com
\end{abstract}




\section{INTRODUÇÃO}

O conhecimento da estrutura da governança corporativa adotada pela empresa pode ser admitida como demanda do investidor antecedente à tomada de decisão sobre participação e continuidade no negócio. Isso porque as características da governança sinalizam a extensão do compromisso dos gestores com objetivo de não expropriar direitos dos acionistas e maximizar a sua riqueza (TERRA; LIMA, 2006).

Para Brandão e Crisóstomo (2015), Brandão et al. (2014), Santos, Vasconcelos e De Luca (2015), Silveira et al. (2009), as características da governança corporativa auxiliam na compreensão da qualidade dos mecanismos de monitoramento dos agentes e no alinhamento de interesses entre proprietários e gestores. Além disso, Silveira et al. (2009) explicam que as firmas podem apresentar padrões de governança diferentes, ainda que pertençam a um mesmo país, isso devido as suas diversas características, sendo importante compreendê-las.

Terra e Lima (2006) explicam que a governança corporativa rege os princípios sobre os quais o processo decisório da empresa é articulado. Em mercados onde há fraca proteção legal dos investidores, e elevada concentração acionária, compreender os aspectos da governança e as variáveis que sobre eles se impõem ajuda no entendimento do funcionamento dos mercados (BRANDÃO; CRISÓSTOMO, 2015; TERRA; LIMA, 2006).

Os estudos realizados por Maia, Vasconcelos e De Luca (2013), Brandão et al. (2014), Santos, Vasconcelos e De Luca (2015) documentaram que as características da estrutura de governança corporativa podem auxiliar no processo de inserção em mercados estrangeiros. Nas pesquisas de Lameira e Ness Júnior (2011), Mapurunga, Ponte e Oliveira (2015), são diversos fatores endógenos e exógenos que podem explicar a governança corporativa. Juntamente com Silveira et al. (2009) esses estudos denotam que os achados observados constituem um campo que demanda maior investigação, pois os resultados ainda se mostram inconsistentes.

A governança corporativa é importante porque não engloba apenas a relação agente e proprietário, ela abrange um conjunto de instrumentos gerenciais instituídos com o propósito de convergir os múltiplos interesses relacionados à firma, alinhando as expectativas econômicas de acionistas minoritários e controladores, gestores, credores e as demais partes interessadas no negócio (TERRA; LIMA, 2006). Essa variabilidade de interesses expõe a governança como um instrumento de gestão constituído de múltiplas dimensões, como demonstram Lameira e Ness Júnior (2011), Mapurunga, Ponte e Oliveira (2015).

O conflito de interesses entre as partes relacionadas, denominado conflito de agência, é danoso ao objetivo de maximização do valor da empresa e ameaça a continuidade do negócio, porque os gestores buscam maximizar a sua utilidade, em detrimento dos financiadores da firma. A governança corporativa, portanto, atua mitigando ou eliminando as chances de que esses problemas acarretem custos para a empresa.

As características da governança corporativa explicam como os conflitos de agência são combatidos em um ambiente econômico onde a informação é imperfeita e existe assimetria informacional. Sabe-se que o comportamento da gestão não é presumível e ela possui acesso à informação que os demais stakeholders não têm (AKERLOF, 1970; MYERS; MAJLUF, 1984; TERRA; LIMA, 2006; LOPES, 2012; SUNDER, 2014).

A literatura (ALMEIDA et al., 2010; ARAÚJO et al., 2017; BRANDÃO et al., 2014; BRANDÃO; CRISÓSTOMO, 2015; LAMEIRA; NESSE JÚNIOR, 2011; MAPURUNGA; PONTE; OLIVEIRA, 2015; SILVEIRA et al., 2009; SILVEIRA; BARROS, 2008) evidencia que a governança corporativa é um construto complexo, constituído de algumas dimensões que compõem o campo de atuação desse instrumento. Esses estudos demonstram que a estrutura da governança pode ser explicada por diversos fatores relacionados às organizações.

Diante do exposto, esta pesquisa responde a seguinte questão: como se caracteriza a governança corporativa nas maiores empresas de capital aberto do Brasil considerando-se as dimensões: estrutura de propriedade e controle, auditoria e conselho fiscal, conselho de administração e constituição de comitês, e relacionamento com os investidores?

O objetivo geral desta pesquisa é caracterizar a governança corporativa nas maiores empresas de capital aberto do Brasil sob uma abordagem multidimensional. Tem-se definidos como objetivos específicos: (i) verificar os possíveis fatores determinantes da governança corporativa e (ii) relacionar esses fatores com as quatro dimensões da governança corporativa.

A realização do presente estudo se justifica na medida em que explora a segmentação da governança corporativa em dimensões, aspecto ainda não suficientemente investigado pela literatura. Enquanto que a maioria das pesquisas trata a governança como um construto único, a abordagem segundo dimensões pode ajudar a explicar diferentes esforços das firmas segundo as áreas de atuação, como propriedade, auditoria, alta gestão e relacionamento externo. Cunha e Politelo (2013) apontam essa como uma limitação dos estudos nacionais.

A identificação de fatores relacionados à governança corporativa tem o intuito de reunir evidência que possa ajudar o direcionamento e a atuação dos controles no monitoramento dos agentes. A escolha das maiores firmas abertas, para análise, se ampara na representatividade econômica e no volume financeiro dessas companhias na bolsa de valores. Essa condição expõe as empresas a um nível maior de pressão por informações confiáveis e qualificadas, além de maior combate aos problemas de agência que venham a impactar negativamente o valor. 


\section{REFERENCIAL TEÓRICO 2.1 Governança corporativa}

As contribuições e os benefícios da governança corporativa para a gestão das empresas estão relacionados com a separação entre controle e propriedade. Assim, os gestores ou agentes são delegados pelos proprietários para administrar os ativos e gerar valor segundo os interesses esperados pelos sócios.

Nessa mudança de paradigma, os gestores possuem vantagem frente os proprietários por terem acesso à informação privilegiada sobre o negócio. De acordo com a teoria da agência, os agentes podem atuar em benefício privado, expropriando os acionistas, caracterizando-se o conflito de interesses (JENSEN; MECKLING, 1976; MYERS; MAJLUF, 1984).

Com o intuito de minimizar ou até eliminar os conflitos de interesse possibilitados pela separação entre controle e propriedade nas firmas modernas, custos de agência são necessários. Esses custos estão associados aos mecanismos de controle existentes na busca pelo alinhamento de interesses entre agente e proprietário. A governança corporativa é um importante mecanismo de monitoramento que eleva os custos de agência, porque não se pode prever o comportamento do gestor (JENSEN; MECKLING, 1976).

Por outro lado, a teoria da agência sugere que custos com quebra de contratos e desvios de conduta da gestão são mais danosos ao valor da empresa. De acordo com Lameira e Ness Júnior (2011), a teoria econômica demonstra que existe uma importante parcela dos problemas das corporações modernas relacionada à separação entre controle e propriedade.

Para Almeida et al. (2010), os conflitos de agência estão intimamente relacionados ao momento que ocorre a separação entre a figura do proprietário, que antes acumulava duas funções, e do gestor. Tal desagregação de papéis na firma, viabiliza a geração de conflitos de interesses entre as diversas partes relacionadas (acionista e gestor, controlador e minoritário) (LAMEIRA; NESS JÚNIOR, 2011); nesse contexto que se insere a governança corporativa.

A governança corporativa, ao relacionar-se com o estudo do governo da empresa e de sua estrutura societária (ALMEIDA et al., 2010), pode trazer benefícios às empresas na medida em que auxilia a otimização da utilização dos seus recursos, sejam eles reais ou potenciais (LAMEIRA; NESS JÚNIOR; MACEDO-SOARES, 2007).

Isso aconteceria devido ao fato de que a governança corporativa está vinculada a certos princípios (equidade, transparência, ética, dever de prestar contas e obediências às leis) que servem de base para a definição das decisões tomadas nas empresas (VIEIRA et al., 2011). Conforme explicado por Almeida et al. (2010), a governança corporativa incentiva uma gestão mais transparente, além de ajudar a reduzir a assimetria informacional e o conflito de agência.

Considerando-se que a redução da concentração da propriedade nas empresas provoca a dispersão do controle, segundo Ripamonti e Kayo (2016), os acionistas majoritários, apesar dessa redução, buscam assegurar o controle através de outras formas. Isso não aconteceria com a mesma facilidade no caso dos acionistas minoritários. Esse cenário pode afetar o retorno dos acionistas menos favorecidos e, por essa razão, a proteção dos minoritários é o maior foco da governança corporativa, visto que a mesma é considerada uma alternativa acessível de captação de recursos com menores custos (TERRA; LIMA, 2006).

Silveira e Barros (2008) afirmam que a governança corporativa pressupõe a adoção de um conjunto de mecanismos internos e externos de controle que alinham interesses de gestores e acionistas, promovendo redução dos prejuízos causados por conflitos de interesses existentes entre proprietários e agentes. Dessa maneira, a adoção de práticas de governança corporativa cada vez mais sofisticadas promove o "desenvolvimento de melhores estruturas organizacionais e a busca de uma melhor dinâmica no seu funcionamento, o que deve possibilitar o aumento da eficiência das empresas, queda nos riscos e, em consequência, uma melhor avaliação por parte do mercado" (LAMEIRA; NESS JÚNIOR, 2011, p. 35).

A governança corporativa insere-se, então, como instrumento que contribui para a minimização de conflitos existentes no ambiente de uma empresa, gerando maior segurança perante o público interno e externo (MAPURUNGA; PONTE; OLIVEIRA, 2015). Destarte, torna-se possível preservar o relacionamento entre gestores, credores, acionistas minoritários e controladores com foco na maximização do valor da firma e no retorno atribuído aos acionistas (TERRA; LIMA, 2006).

A minimização desses conflitos contribui para o fortalecimento do mercado acionário (ALMEIDA et al., 2010). Essa proposição é também corroborada por Vieira et al. (2011) ao identificarem que a adoção de práticas de governança favorece a otimização do desempenho empresarial e do mercado de capitais. Assim, a adoção de práticas de governança corporativas mais sofisticadas pode corroborar o desenvolvimento de melhores estruturas organizacionais e dinâmicas mais eficientes do seu funcionamento (LAMEIRA; NESS JÚNIOR, 2011).

Nesse sentido, a identificação dos principais aspectos da governança corporativa sugere, portanto, a relevância de sua caracterização. Apontar que características das empresas, internas ou externas, poderiam impulsionar ou mesmo dificultar a governança corporativa, levaria à condução da gestão sob um enfoque mais eficiente estrategicamente.

\subsection{Determinantes da governança e hipóteses de pesquisa}

A literatura que investiga as práticas de governança corporativa comumente assume postura pautada no estudo do determinismo. Logo, presume-se que há aspectos favoráveis ou não à adoção de mecanismos que alinhem interesses entre gestores, proprietários e os demais stakeholders. Essa postura é sustentada pela ideia de que o aperfeiçoamento de práticas de governança corporativa está relacionado ao aprimoramento das estruturas organizacionais, uma vez que a governança está ligada aos mecanismos que regem o processo decisório (TERRA; LIMA, 2006; LAMEIRA; NESS JÚNIOR, 2011). 


\subsubsection{Níveis diferenciados de governança corporativa}

A criação dos níveis diferenciados de governança corporativa (Novo Mercado, N2 e N1) é uma iniciativa da B3 (Brasil, Bolsa, Balcão) que aumenta a proteção dos direitos minoritários (LEMEIRA; NESS JÚNIOR; MACEDO-SOARES, 2007). E por tal razão, para Mapurunga, Ponte e Oliveira (2015), essa é uma característica que pode influenciar a governança corporativa adotada nas empresas. As firmas que aderem a quaisquer dos níveis (NM, N2 ou N1) necessitam se enquadrar a padrões com maior grau de rigidez de transparência e governança corporativa.

Presume-se que a participação da empresa nos níveis diferenciados está relacionada com o maior comprometimento da gestão junto a práticas de governança corporativa, ênfase no investidor local, atenção às normas, demanda de investidores e instituições (LEMEIRA; NESS JÚNIOR; MACEDO-SOARES, 2007; SILVEIRA; BARROS, 2008).

Conforme ressaltam Oliveira, Oddone e Albuquerque (2008), que assuem como uma estratégia a governança corporativa, uma política de práticas transparentes e coerentes com a prestação de informações sobressai mediante a adesão aos níveis diferenciados. Deste exposto, a presente pesquisa sugere a seguinte hipótese:

$\mathbf{H}_{1}$ : a participação da empresa em quaisquer dos níveis diferenciados de governança corporativa da B3 influencia positivamente a qualidade da governança corporativa.

\subsubsection{Emissão de American Depositary Receipt (ADR)}

A internacionalização assumida como uma orientação estratégica que pode impactar a governança corporativa, porque as exigências competitivas do mercado internacional tendem a ser superiores àquelas observadas apenas no país de origem, conforme Santos, Vasconcelos e De Luca (2015). A emissão de ADR é uma forma de inserir a empresa no mercado internacional (SOUZA; MURCIA; MARCON, 2011) e a governança corporativa se mostra como opção para diminuir os custos, riscos e a percepção de incerteza do investidor no ambiente internacional, (SANTOS; VASCONCELOS; DE LUCA, 2015).

De acordo com os estudos de Silveira e Barros (2008), Silveira et al. (2009), Mapurunga, Ponte e Oliveira (2015), a inserção internacional mediante a emissão de ADR no mercado norte-americano sugere enquadramento da firma a padrões mais rígidos de governança corporativa. Do exposto, a presente pesquisa sugere a seguinte hipótese:

$\mathbf{H}_{2}$ : a emissão de ADR influencia positivamente a qualidade da governança corporativa.

\subsubsection{Endividamento}

Assumindo-se que as exigências dos stakeholders podem impactar o estabelecimento dos mecanismos de controle e monitoramento, é possível destacar o nível de endividamento como fator capaz de influenciar a qualidade da governança corporativa. A concessão de crédito está atrelada à existência prévia de garantias, que, para Mapurunga, Ponte e Oliveira (2015), relaciona-se com a existência de maior segurança para os credores. De acordo com as autoras, essa maior proteção provém da adoção de melhores práticas de governança corporativa.

Firmas sob crescimento e com grande demanda de financiamento externo têm maiores incentivos para estabelecer melhores práticas de governança de modo a diminuir o custo de capital (KLAPPER; LOVE, 2004). Lameira e Ness Júnior (2011) também concordam que as melhores práticas de governança corporativa viabilizam a redução de custos de captação na medida em que há o aperfeiçoamento dos diversos processos dentro da empresa.

Dessa forma argumenta-se que as firmas que buscam ou possuem níveis elevados de endividamento tendem a apresentar melhor governança. O objetivo é sinalizar a existência de maiores garantias aos stakeholders da atividade empresarial visando manter a contratação de novas dívidas. Assim, é estabelecida como hipótese:

$\mathbf{H}_{3}$ : o endividamento influencia positivamente a qualidade da governança corporativa.

\subsubsection{Tamanho}

O tamanho de uma empresa é constantemente elencado como determinante da adoção de melhores práticas de governança corporativa (ALMEIDA et al., 2010; MAPURUNGA. PONTE; OLIVEIRA, 2015). Entretanto, ele também é tido como aspecto de relação incerta (KLAPPER; LOVE, 2004; CUNHA; POLITELO, 2008; SILVEIRA et al., 2009; ZAGO; MELLO, 2014), porque empresas com diferentes portes podem demonstrar melhores estruturas de governança corporativa.

Conforme argumentam Klapper e Love (2004), empresas menores podem desenvolver elevada oportunidade de crescimento, aumentando a sua demanda por capital externo e, em virtude disso, a necessidade de se estabelecerem mecanismos que incrementem a percepção de segurança para os agentes financiadores. Por outro lado, os autores destacam que empresas de grande porte podem apresentar maiores problemas de agência, demandando mecanismos de governança corporativa mais rígidos.

Além desses pontos, acrescenta-se que o maior volume de recursos financeiros pode facilitar a implantação de práticas de governança corporativa mais dispendiosas e sofisticadas (SILVEIRA et al., 2009). Nesse caso, isso pode levar a maiores adesões das práticas por firmas de elevado porte. Dessa forma, delineia-se a seguinte hipótese:

$\mathbf{H}_{4}$ : o tamanho associa-se com a qualidade da governança corporativa. 


\subsubsection{Valor}

O valor denota a avaliação realizada pelos investidores sobre a capacidade da firma de gerar riqueza. Ele expressa, monetariamente, elementos não diretamente observáveis, dentre os quais se insere a governança corporativa, constituída como forma de minimizar os múltiplos conflitos de interesse e maximizar o valor da firma (ZAGO; MELLO, 2014). Esse raciocínio é razoável, pois há maiores garantias de não acontecer expropriação dos acionistas minoritários (SILVEIRA; BARROS, 2008; SILVEIRA et al., 2009), visto que a função utilidade dos agentes econômicos tem alinhamento com os interesses dos proprietários.

Assim, considerando-se que diferenças no crescimento das oportunidades que não sejam observáveis podem interferir no nível de governança corporativa de uma entidade (KLAPPER; LOVE, 2004), pode-se presumir que a existência de elementos, sobretudo intangíveis, afetam a definição de tais mecanismos. Recursos de natureza intangível têm mais chances de serem desviados, porque têm o monitoramento dificultoso e dispendioso.

Silveira e Barros (2008) e Silveira et al. (2009) argumentam sobre a tangibilidade dos ativos empresariais e destacam que firmas com muitos intangíveis devem sinalizar ao mercado que não há má utilização dos recursos. Presume-se, portanto, haver a indicação de relação entre o valor da firma e a governança corporativa. Isto posto, tem-se a seguinte hipótese:

$\mathbf{H}_{5}$ : o valor da firma influencia positivamente a qualidade da governança corporativa.

\subsubsection{Desempenho}

De acordo com Lameira e Ness Júnior (2011), na busca pelo crescimento do retorno dos acionistas e pela maximização do valor da firma, as empresas devem perseguir, dentre outras metas, a melhoria do seu desempenho. Destarte, a adoção de melhores práticas de governança corporativa é assumida como um dos instrumentos que viabilizam o alcance dessas metas, pois o processo decisório é aperfeiçoado, promovendo maior eficiência gerencial, melhor alocação de recursos e aprimoramento dos controles sobre o patrimônio da firma.

Empresas com melhor desempenho estão predispostas a sofrer maiores exigências por parte dos investidores, incentivando o aumento dos mecanismos de governança corporativa de modo a promover melhoria no monitoramento da gestão (CUNHA; POLITELO, 2013). Silveira et al. (2009) complementam que firmas com melhor desempenho operacional podem apresentar maior propensão em investir em mecanismos mais acurados de governança corporativa.

Presume-se que a existência de maior disponibilidade de recursos na empresa decorrente dos altos níveis de desempenho favorece a implementação de mecanismos de governança mais robustos. A disponibilidade de recursos resultantes da retroalimentação do resultado favorável sugere maior controle e monitoramento sobre os ativos, evitando desvios do objetivo de alinhar os interesses. Do exposto, sugere-se a seguinte hipótese:

$\mathbf{H}_{6}$ : o desempenho influencia positivamente a qualidade da governança corporativa.

\section{PROCEDIMENTOS METODOLÓGICOS 3.1 Classificação da pesquisa e definição da amostra}

Esta pesquisa possui natureza descritiva, uma vez que está voltada para a caracterização da governança corporativa e de sua relação com fatores determinantes em um agrupamento específico de empresas (COLLIS; HUSSEY, 2005). Esta pesquisa pode ser classificada ainda como documental, isso porque fez-se utilização de dados secundários extraídos mediante leitura e análise de diversos relatórios publicados pelas firmas, dentre os quais Balanço Patrimonial, Demonstração do Resultado do Exercício, Formulário de Referência e Formulário Cadastral, disponíveis na B3 - Brasil, Bolsa, Balcão (anteriormente chamada BM\&FBovespa). Além dessas fontes, foram obtidos dados nos portais institucionais (websites) das empresas e do Banco J.P. Morgan. Quanto à abordagem de análise de dados, a pesquisa é qualitativa e quantitativa.

Os resultados são analisados sob enfoque descritivo, de caracterização das variáveis e como essa descrição reflete a amostra. Depois segue a análise quantitativa, com emprego de ferramentas estatísticas (regressão linear múltipla e correlação) de inferência.

A amostra analisada é não probabilística, derivada do grupo das maiores empresas de capital aberto do Brasil, segundo a Revista Exame Melhores e Maiores (2016). A literatura sugere que maiores empresas possuem estrutura mais complexa, demando esforços superiores no que se refere à estrutura de governança corporativa. Soma-se a isso o fato de que as firmas maiores detêm capacidade econômico-financeira para suprir os custos de agência (KLAPPER; LOVE, 2004; SILVEIRA et al., 2009).

O grupo considerado reúne empresas marcadas pela representatividade econômica e por robusto volume financeiro na bolsa de valores brasileira, resguardando-se a heterogeneidade setorial da amostra. No campo de estudo da governança, Beuren e Silva (2015), Cardoso, De Luca e Almeida (2016), Klann, Kreuzberg e Beck (2014), Santos, Vasconcelos e De Luca (2015), recorreram à amostragem semelhante.

A coleta dos dados ocorreu entre os meses de janeiro a março/2017. Por essa razão, os dados contemplados na pesquisa aludem ao período contábil encerrado em 31/12/2015, pois ainda não tinham sido publicadas demonstrações financeiras mais recentes. Do grupo descrito, havia inicialmente 100 empresas, das quais optou-se pela exclusão daquelas pertencentes ao setor financeiro.

O procedimento é comum nos estudos que analisam aspectos da estrutura de capital das firmas, caso de Fonseca, Silveira e Hiratuka (2016), Ripamonti e Kayo (2016), Araújo et al. (2017). Segundo Kayo, The e Basso (2006), deve-se optar pela retirada dessas empresas porque há regulamentações e particularidades que afetam o setor.

O novo grupo passou a ser composto de 82 empresas. Porém, na etapa de coleta de dados uma empresa não tinha 
disponibilizado o Formulário de Referência, sendo também preterida, como mostra a Tabela 1.

Tabela 1 - Amostra da pesquisa

\begin{tabular}{ll} 
Amostra inicial - Maiores empresas de capital aberto & 100 \\
(-) Empresas do setor financeiro & 18 \\
(-) Empresas com dados indisponíveis & 1 \\
(=) Amostra final & 81 \\
\hline
\end{tabular}

Fonte: dados da pesquisa.

Em resumo, a amostra estudada é composta de 81 empresas de capital aberto não financeiras derivadas de amostragem não probabilística.

\subsection{Variáveis}

A governança corporativa, variável dependente, é mensurada nesta pesquisa a partir de um índice amplo de aspectos, segregados em quatro diferentes dimensões: (i) estrutura de propriedade e controle; (ii) auditoria e conselho fiscal; (iii) conselho de administração e constituição de comitês; (iv) relacionamento com investidores.

Essa medida, adaptada de Lameira e Ness Júnior (2011), mostra-se detalhada a partir do Quadro 1. O índice que mensura a governança corporativa (Igov) é composto por 12 aspectos binários, que permeiam os itens $1.1,1.2, \ldots, 4.1,4.2$. Dessa forma, ao verificar as fontes de coleta dos dados, havendo concordância com a assertiva do item correspondente, atribui-se valor "1"; nos casos em que ocorria o oposto, atribuiu-se valor "0". Essa forma de avaliação é um mitigador de problemas decorrentes da consideração de aspectos restritos, desconsiderando a existência de diferentes dimensões da governança corporativa.

Quadro 1 - Base de mensuração da governança corporativa (Igov)

\begin{tabular}{|c|c|c|}
\hline Item & Dimensão 1 - Estrutura de propriedade e controle & Fonte de Coleta dos Dados \\
\hline 1.1 & O controlador (ou grupo controlador) possui menos de $50 \%$ das ações ordinárias & $\begin{array}{l}\text { Formulário de Referência Item } \\
15.1 / 2 \text { - Posição Acionária }\end{array}$ \\
\hline 1.2 & O percentual de ações preferenciais é inferior a $20 \%$ do total do capital & $\begin{array}{l}\text { Formulário de Referência Item } 17.1 \\
\text { - Informações Capital Social }\end{array}$ \\
\hline Item & Dimensão 2 - Auditoria e conselho fiscal & Fonte de Coleta dos Dados \\
\hline 2.1 & A empresa é auditada por uma Bigfour (Price, KPMG, Delloite, Ernst \& Young) & $\begin{array}{l}\text { Demonstrações Financeiras Padro- } \\
\text { nizadas - Pareceres e Declarações }\end{array}$ \\
\hline 2.2 & $\begin{array}{l}\text { Não houve parecer da auditoria com discordância de opinião/ressalva nas demons- } \\
\text { trações financeiras padronizadas }\end{array}$ & $\begin{array}{l}\text { Demonstrações Financeiras Padro- } \\
\text { nizadas - Pareceres e Declarações }\end{array}$ \\
\hline 2.3 & A empresa possui conselho fiscal permanente & $\begin{array}{l}\text { Formulário de Referência Item } 12.2 \\
\text { - Estrutura administrativa }\end{array}$ \\
\hline Item & Dimensão 3 - Conselho de administração e constituição de comitês & Fonte de Coleta dos Dados \\
\hline 3.1 & Os administradores possuem participação nos lucros & $\begin{array}{l}\text { Formulário de Referência Item } 13.1 \\
\text { - Política/prática de remuneração }\end{array}$ \\
\hline 3.2 & O conselho de administração possui entre 5 e 9 membros & $\begin{array}{l}\text { Formulário de Referência Item } \\
\text { 12.6/8 - Composição e experiência } \\
\text { profissional da administração e } \\
\text { conselho fiscal }\end{array}$ \\
\hline 3.3 & Mais de $50 \%$ dos conselheiros são independentes & $\begin{array}{l}\text { Formulário de Referência Item } \\
12.6 / 8 \text { - Composição e experiência } \\
\text { profissional da administração e } \\
\text { conselho fiscal }\end{array}$ \\
\hline 3.4 & O presidente do conselho não é diretor ou controlador da empresa & $\begin{array}{l}\text { Formulário de Referência Item } \\
\text { 12.6/8 - Composição e experiência } \\
\text { profissional da administração e } \\
\text { conselho fiscal }\end{array}$ \\
\hline 3.5 & A empresa possui qualquer tipo de comitê constituído e evidenciado & $\begin{array}{l}\text { Formulário de Referência Item } 12.2 \\
\text { - Estrutura administrativa }\end{array}$ \\
\hline Item & Dimensão 4 - Relacionamento com investidores & Fonte de Coleta dos Dados \\
\hline 4.1 & A empresa não teve reapresentação de demonstrações contábeis no período & $\begin{array}{l}\text { Demonstrações Financeiras Padro- } \\
\text { nizadas }\end{array}$ \\
\hline 4.2 & A empresa possui em seu portal eletrônico área dedicada à governança corporativa & $\begin{array}{l}\text { Portal virtual (website) de cada } \\
\text { empresa }\end{array}$ \\
\hline
\end{tabular}

Fonte: Adaptado de Lameira e Ness Júnior (2011). 
Definido esse critério, também adotado nos estudos de Lameira e Ness Júnior (2011), Mapurunga, Ponte e Oliveira (2015), foi estabelecida a medida do Igov com base na equação (1) apresentada a seguir:

$$
\operatorname{Igov}_{i}=\frac{\text { Pontuação total obtida pela empresa }_{i}}{\text { Pontuação total possível }}
$$

Portanto, o Igov $(0 \leq \operatorname{Igov} \leq 1)$ é a medida para a qualidade da governança corporativa das empresas estudadas. Quanto maior o Igov obtido, maior é a adesão da empresa às práticas estabelecidas nesta pesquisa, admitindo-se com isso melhor qualidade da governança. Esse índice foi ainda decomposto para fins de análise da governança corporativa com enfoque em cada uma das dimensões do Igov. Com isso, cada empresa "i” obteve, após a coleta dos dados, um índice geral de governança corporativa (Igov) e outros quatro índices específicos para cada dimensão (1, 2, 3 e 4). A pontuação total possível, nesses casos, é função dos itens da dimensão analisada. Cada um dos índices específicos é similar ao Igov em sua forma de mensuração e variam no intervalo fechado entre 0 e 1.

Quanto maior o índice específico, maior é a adesão à governança, mas em relação aos aspectos de cada dimensão individual. Viabilizando essa análise, foram identificadas aquelas dimensões com o maior e menor nível de adesão. Buscava-se ainda verificar os possíveis fatores associados à governança corporativa em cada dimensão especificamente.

A literatura sobre governança corporativa sugere que alguns fatores podem se mostram determinantes da qualidade da governança corporativa. Enumeram-se na presente pesquisa alguns desses fatores no Quadro 2, denominando-se a variável contemplada pela investigação, forma de mensuração, fontes de coleta dos dados e a base teórica subjacente.

Quadro 2 - Detalhamento das variáveis independentes aplicadas no modelo de regressão

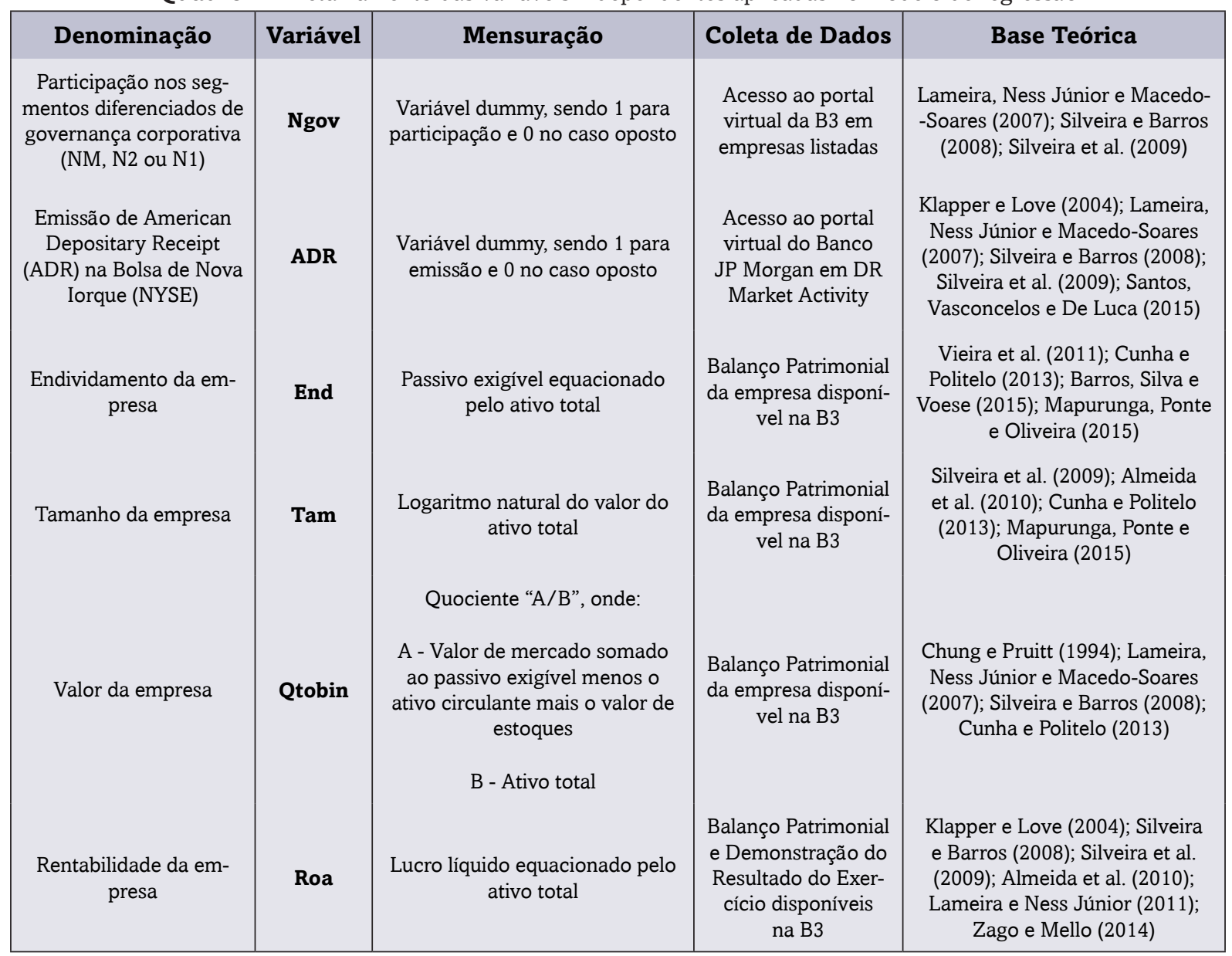

Fonte: Elaborado pelos autores com base na revisão da literatura.

Apesar do rigor metodológico adotado na pesquisa, deve-se ressaltar que há limitações. O estudo não esgota os aspectos da governança corporativa, tampouco suas dimensões. Da mesma forma, não estão contemplados aqui outros fatores que poderiam sinalizar a relação com a governança corporativa das empresas. Destarte, outras variáveis poderiam incorporar novas pesquisas com escopo similar àquele proposto neste estudo. Generalizações quaisquer sobre os resultados da pesquisa devem considerar essas e outras limitações. 


\subsection{Delineamento da análise quantitativa}

À consecução dos objetivos específicos do estudo, foram definidas duas abordagens no delineamento da análise quantitativa. Para alcance do primeiro objetivo específico, recorreu-se à regressão linear múltipla, estimada pelo método dos mínimos quadrados ordinários. Sua aplicação permite verificar se variáveis independentes exercem influência sobre uma variável dependente. Nesta pesquisa, a variável dependente é o Igov, detalhada no Quadro 1; as variáveis independentes (Ngov, ADR, Tam, Qtobin, Roa e End) são discriminadas conforme o Quadro 2. Estabelecidas as variáveis descritas nos Quadros 1 e 2, formulou-se o modelo econométrico da equação 2.

$$
\operatorname{Igov}_{i}=\alpha_{0}+\beta_{1} \text { Ngov }_{i}+\beta_{2} A D R_{i}+\beta_{3} \text { End }_{i}+\beta_{4} \operatorname{Tam}_{i}+\beta_{5} \text { tobin }_{i}+\beta_{6} \operatorname{Roa}_{i}+\varepsilon_{i}
$$

Para alcance do segundo objetivo específico, recorreu-se à análise de correlação com estimador não paramétrico de Spearman. Sua aplicação permite investigar o grau de correlação entre duas variáveis, não se assumindo causalidade entre elas. Procedeu-se com o teste entre os índices específicos de governança corporativa em cada dimensão (1, 2, 3 e 4) e os possíveis fatores determinantes. Na presente pesquisa foram estimadas então seis correlações para cada índice específico. O estimador não paramétrico foi usado, porque todos os índices específicos violaram a suposição de normalidade (Sig. < 0,05). A análise quantitativa deu-se a partir do uso do software Statistical Package for the Social Sciences (SPSS).

\section{APRESENTAÇÃO, ANÁLISE E DISCUSSÃO DOS RESULTADOS 4.1 Caracterização da governança corporativa}

Na Tabela 2 é apresentada a estatística descritiva da governança corporativa e respectivas dimensões utilizadas como base para o cálculo do referido índice de governança.

Tabela 2 - Estatística descritiva da governança corporativa e dimensões

\begin{tabular}{lccccc}
\hline \multicolumn{1}{c}{ Medidas Descritivas } & Igov & Dimensão 1 & Dimensão 2 & Dimensão 3 & Dimensão 4 \\
\hline Média & $67 \%$ & $69 \%$ & $73 \%$ & $55 \%$ & $87 \%$ \\
Mediana & $67 \%$ & $50 \%$ & $67 \%$ & $60 \%$ & $100 \%$ \\
Mínimo & $33 \%$ & $0 \%$ & $33 \%$ & $0 \%$ & $0 \%$ \\
Máximo & $92 \%$ & $100 \%$ & $100 \%$ & $100 \%$ & $100 \%$ \\
Desvio Padrão & $13 \%$ & $30 \%$ & $18 \%$ & $20 \%$ & $23 \%$ \\
Coeficiente de Variação & $19 \%$ & $44 \%$ & $24 \%$ & $36 \%$ & $27 \%$ \\
\hline
\end{tabular}

Fonte: dados da pesquisa

Ao analisar a Tabela 2 é possível identificar que as empresas da amostra apresentaram adesão mínima a 4 (33\%) dos 12 dos aspectos referentes à qualidade da governança corporativa (Igov). A adoção de melhores práticas de governança é satisfatória em pelo menos metade da amostra, indicada pela mediana de $67 \%$. Entretanto, nenhuma empresa da amostra apresentou adesão total às práticas de governança corporativa elencadas neste estudo, posto que o Igov máximo é de $92 \%$. Apesar disso, observou-se que houve pelo menos uma empresa com adesão plena, em cada dimensão, ao índice adaptado de Lameira e Ness Júnior (2011).

Dentre as dimensões, a quarta, que se refere ao relacionamento com investidores, é a que mostrou maior adesão. Assim, pode-se conjecturar que, quando comparada com as demais dimensões, os gestores dispensam maior atenção à imagem da firma, além da relação junto aos investidores. Isso pode ocorrer devido ao fato de que os aspectos relacionados à reapresentação de demonstrações contábeis e à área no website institucional dedicada à governança corporativa têm impacto direto na avaliação da empresa pelos investidores, nos relacionamentos externos construídos e na avaliação de outros agentes que se relacionam com a firma, sejam credores, sociedade e demais stakeholders.

A análise da qualidade da governança corporativa das empresas também foi realizada sob a perspectiva de cada dimensão. Na Tabela 3, portanto, são expostos os resultados alusivos à dimensão estrutura de propriedade e controle.

Tabela 3 - Adesão das empresas aos itens da primeira Dimensão 1

\begin{tabular}{clcc}
\hline Item & Dimensão 1 - Estrutura de propriedade e controle & \multicolumn{2}{c}{ Empresas } \\
\hline 1.1 & O controlador (ou grupo controlador) possui menos de 50\% das ações ordinárias & 37 & $46 \%$ \\
1.2 & O percentual de ações preferenciais é inferior a 20\% do total do capital & 75 & $93 \%$ \\
\hline
\end{tabular}

Fonte: dados da pesquisa 
Nesta dimensão, 46\% das empresas que compõem a amostra possuem o seu controlador com menos da metade das ações ordinárias. Problemas de assimetria informacional e tomada de decisões de forma discricionária podem ser, então, gerados como consequência dessa alta concentração acionária nos outros 54\%, prejudicando a qualidade da governança corporativa. Por outro lado, verifica-se que a grande maioria das empresas (93\%) tem a composição do capital formado predominantemente por ações ordinárias. Esse cenário sinaliza ao mercado um indicativo do grau confiabilidade associado à gestão, posto que as ações preferenciais não proporcionam ao seu detentor direitos essenciais de fiscalização e participação na decisão dos rumos do negócio.

O resultado encontrado quanto a esse último aspecto contrasta com o que foi verificado por Silveira e Barros (2008), que, ao analisarem 161 empresas não financeiras da hoje chamada B3 no exercício de 2002, identificaram que as ações preferenciais correspondiam a menos da metade das ações em apenas 38,5\% das empresas. Dessa forma, evidencia-se que as empresas aprimoraram os mecanismos de governança, talvez condicionadas pelo imperativo regulatório de instituições como a Comissão de Valores Mobiliários (CVM) e a B3. Esse contraste ainda evidencia o processo de aperfeiçoamento do mercado de capitais brasileiro, o que pode trazer ganhos no que diz respeito à percepção dos investidores.

$\mathrm{Na}$ Tabela 4 são evidenciados os resultados relativos à segunda dimensão do índice de governança corporativa, que trata da auditoria e conselho fiscal.

Tabela 4 - Adesão das empresas aos itens da Dimensão 2

\begin{tabular}{clr}
\hline Item & Dimensão 2 - Auditoria e conselho fiscal & Empresas \\
\hline 2.1 & A empresa é auditada por uma Bigfour (Price, KPMG, Delloite, Ernst \& Young) & 74 \\
2.2 & $\begin{array}{l}\text { Não houve parecer da auditoria com discordância de opinião/ressalva nas demonstrações financei- } \\
\text { ras padronizadas }\end{array}$ & 76 \\
2.3 & A empresa possui conselho fiscal permanente & $94 \%$ \\
\hline
\end{tabular}

Fonte: dados da pesquisa

Identificou-se alta adesão das empresas a dois dos três aspectos analisados na referida dimensão. Na medida em que tais itens aludem a auditoria externa e fiscalização, sinaliza-se maior atenção com aspectos da fidedignidade e confiabilidade das informações contábeis. O enfoque dado ao controle externo pode ser resultado da demanda informacional exigida pelos investidores, analistas e os órgãos de controle. Assim, as empresas passam a buscar meios de fiscalização mais confiáveis frente ao público externo.

Esses resultados são similares àqueles encontrados por Santos, Vasconcelos e De Luca (2015) que investigaram a relação entre a internacionalização e a governança corporativa das maiores empresas listadas na B3, em 2012. Os autores apontam que a existência de poucas empresas com conselho fiscal permanente pode ser vista como uma deficiência, pois o órgão apresenta função de fiscalização e ajuda a evitar desvios de conduta e oportunismo. Porém, a instituição do conselho fiscal permanente pode ser dispendiosa, explicando esse resultado.

Os resultados acerca da terceira dimensão são apresentados na Tabela 5.

Tabela 5 - Adesão das empresas aos itens da Dimensão 3

\begin{tabular}{|c|c|c|c|}
\hline \multirow{2}{*}{ Item } & \multirow{2}{*}{$\begin{array}{l}\text { Dimensão } 3 \text { - Conselho de administração e constituição de comitês } \\
\text { Os administradores possuem participação nos lucros }\end{array}$} & \multicolumn{2}{|c|}{ Empresas } \\
\hline & & 5 & $6 \%$ \\
\hline 3.2 & O conselho de administração possui entre 5 e 9 membros & 61 & $75 \%$ \\
\hline 3.3 & Mais de $50 \%$ dos conselheiros são independentes & 20 & $25 \%$ \\
\hline 3.4 & O presidente do conselho não é diretor ou controlador da empresa & 74 & $91 \%$ \\
\hline 3.5 & A empresa possui qualquer tipo de comitê constituído e evidenciado & 63 & $78 \%$ \\
\hline
\end{tabular}

Fonte: dados da pesquisa

Acerca da terceira dimensão, é possível identificar que as empresas buscam fornecer maior independência e, consequentemente, confiabilidade por meio de seus órgãos colegiados, o que pode ser verificado a partir da elevada aderência em três dos cinco aspectos em análise (3.2, 3.4 e 3.5). A quantidade de membros no conselho de administração pode possibilitar maior eficiência quando da tomada de decisão, evitando concentração de interesses.

A independência do presidente do conselho de administração em relação ao cargo de diretor e à condição de acionista controlador pode fornecer maior confiabilidade à gestão. Além disso, a constituição de outros tipos de comitês pode contribuir para eficiência dos processos decisórios, porque os comitês auxiliam no tratamento de assuntos específicos da administração corporativa, como a gestão de riscos ou a responsabilidade social.

Entretanto, é importante destacar que em apenas $25 \%$ da amostra possuía conselho com mais da metade de seus integrantes independentes. Essa fragilidade prejudica a independência do órgão dentro da empresa, potencializando as chances 
de expropriação dos acionistas, causa de possíveis flutuações na valoração da empresa diante dos futuros investidores.

Por fim, os resultados também relatam a baixa utilização do instrumento de controle relativo à participação do gestor nos lucros (6\%). Esse mecanismo pode promover maior alinhamento de interesses entre agentes e proprietários. Contudo, a remuneração variável também pode resultar no efeito colateral do gerenciamento de resultados.

A caracterização da qualidade da governança corporativa nas empresas é finalizada com a análise dos dados da dimensão relacionamento com investidores, como demonstrado a partir da Tabela 6.

Tabela 6 - Adesão das empresas aos itens da Dimensão 4

\begin{tabular}{clc}
\hline Item & Dimensão 4 - Relacionamento com investidores & Empresas \\
5.1 & A empresa não teve reapresentação de demonstrações contábeis no período & 62 \\
5.2 & A empresa possui em seu portal eletrônico área dedicada à governança corporativa & $77 \%$ \\
\hline
\end{tabular}

Fonte: dados da pesquisa

Nessa dimensão, 77\% das empresas não reapresentaram suas demonstrações no período investigado. A reapresentação de demonstrações normalmente é ocasionada por erros e ajustes das informações contábeis inicialmente publicadas. Assim, a não reapresentação sinaliza ao mercado de capitais o compromisso da gestão e da contabilidade com o disclosure fidedigno e oportuno, aspecto positivo na tomada de decisão eficiente dos stakeholders.

Por outro lado, quase todas as firmas tinham em seu portal eletrônico área dedicada à governança corporativa. Isso funciona como um canal de comunicação e aproximação entre firma, shareholders e stakeholders, que pode explicitar informações sobre estrutura da gestão, prerrogativas, regras e composição do capital humano.

O relacionamento com investidores também é estudado por Terra e Lima (2006), que, ao analisarem 3.682 observações das firmas de maior liquidez listadas na Bovespa (atualmente B3) no período 1995-2002, verificam a reação do mercado quanto à pontualidade na entrega dos demonstrativos financeiros à CVM. Os autores identificaram que a tempestividade fornecia às empresas retorno anormal positivo.

Em oposição, empresas que atrasaram a entrega apresentaram retorno anormal negativo. Esses resultados sustentam a concepção de que as expectativas dos investidores podem ser impactadas pela forma como a empresa constrói e mantém o relacionamento com o stakeholder - aspecto este indicativo da qualidade da governança corporativa, que modifica a percepção de risco dos investidores e, consequentemente, o valor da firma.

\subsection{Aspectos relacionados à governança corporativa}

As análises em torno da regressão linear múltipla devem ser antecedidas pela avaliação da validade e ajuste do modelo econométrico. Destarte, examinou-se sua adequação por meio dos pressupostos de autocorrelação serial, normalidade e homoscedasticidade dos resíduos, e de multicolinearidade das variáveis independentes. Os resultados acerca dos testes de validação e de ajuste do modelo de regressão figuram na Tabela 7.

Tabela 7 - Caracterização e validação do modelo de regressão linear múltipla

\begin{tabular}{ccc}
\hline Aspecto Avaliado & Método de Avaliação & Resultado \\
\hline Significância do modelo & Estatística F (Sig.) & $4,645\left(0,000^{* * *}\right)$ \\
Poder explicativo & $\mathrm{R}^{2}$ ajustado & 0,215 \\
Autocorrelação serial dos resíduos & Estatística Durbin-Watson & 2,079 \\
Normalidade dos resíduos & Teste de Kolmogorov-Smirnov Z (Sig.) & $0,584(0,885)$ \\
Homoscedasticidade dos resíduos & Teste de Pesarán-Pesarán (Sig.) & $0,240(0,877)$ \\
Multicolinearidade & Estatística VIF (Mínimo e Máximo) & 1,027 e 2,888 \\
\hline
\end{tabular}

Nota. ${ }^{\star \star \star}$ significante ao nível de $1 \%$.

Fonte: dados da pesquisa.

A Tabela 7 demonstra que o modelo econométrico da equação 2 é significativo ao nível de 1\%, capaz de explicar cerca de $22 \%$ da variância de Igov. Conforme a estatística de Durbin-Watson, não há autocorrelação serial dos resíduos. As características do modelo, com seis variáveis independentes e 80 observações, sugeria uma estatística entre 1,801 ( $\left.d_{u}\right)$ e 2,199 (4-d $\left.\mathrm{d}_{\mathrm{u}}\right)$, considerando-se 5\% como nível de significância.

A aplicação do teste de Kolmogorov-Smirnov Z atesta normalidade dos resíduos (0,885). O teste de Pesarán-Pesarán, onde o quadrado dos resíduos é função do quadrado dos preditos, todos eles padronizados, é indicativo de que a variância dos resíduos é constante. Por último, a estatística VIF evidenciou que não são observados problemas significativos quanto ao pressuposto de multicolinearidade. Conclui-se que o modelo exposto, sumarizado pela equação 2, é valido para fins de análise dos resultados.

Inferindo-se em favor da adequação do modelo proposto, o primeiro objetivo específico foi alcançado pela pesquisa, evidenciando os aspectos que influenciaram a governança corporativa nas empresas investigadas, como expõe a Tabela 8. 
Tabela 8 - Modelo de regressão linear múltipla: Igov como variável dependente

\begin{tabular}{lccccc}
\hline \multicolumn{1}{c}{ Variáveis Independentes } & $\begin{array}{c}\text { Beta não } \\
\text { padronizado }\end{array}$ & $\begin{array}{c}\text { Beta } \\
\text { padronizado }\end{array}$ & $\begin{array}{c}\text { Estatística } \\
\text { t }\end{array}$ & Sig. & VIF \\
\hline Constante & 0,230 & - & 0,818 & 0,416 & - \\
Participação no NM, N2 ou N1 (Ngov) & 0,135 & 0,434 & 4,327 & $0,000^{\star \star \star}$ & 1,027 \\
Emissão de ADR (ADR) & 0,050 & 0,166 & 1,120 & 0,267 & 2,234 \\
Endividamento (End) & 0,047 & 0,058 & 0,447 & 0,656 & 1,691 \\
Tamanho (Tam) & 0,017 & 0,160 & 0,952 & 0,344 & 2,888 \\
Valor (Qtobin) & 0,026 & 0,126 & 1,089 & 0,280 & 1,367 \\
Desempenho (Roa) & 0,341 & 0,164 & 1,177 & 0,243 & 1,983 \\
\hline
\end{tabular}

Nota. ${ }^{* \star \star}$ significante ao nível de $1 \%$.

Fonte: dados da pesquisa.

Os resultados oriundos da regressão linear múltipla permitem inferir que apenas a variável representativa da participação da empresa nos níveis diferenciados de governança corporativa tem significância estatística. A retirada da variável em questão torna o modelo não significativo. Assim, a inclusão da firma nos segmentos de listagem da B3 gera diferenças representativas e positivas na qualidade da governança corporativa. Esse padrão sinaliza para o mercado de capitais firmas mais comprometidas com os princípios da equidade, transparência, ética, dever de prestar contas e obediências às leis, dentre outros. Os resultados corroboram Silveira et al. (2009), Lameira e Ness Júnior (2011), Mapurunga, Ponte e Oliveira (2015).

Em outra direção, as variáveis que representam emissão de ADR no mercado de capitais norte-americano, endividamento, tamanho, valor e desempenho, não tem influência sobre a qualidade da governança corporativa. Essas inferências são sustentadas por Mapurunga, Ponte e Oliveira (2015) - emissão de ADR; Cunha e Politelo (2013) - endividamento; Cunha e Politelo (2013) e Zago e Mello (2014) - tamanho; Silveira et al. (2009), Almeida et al. (2010) e Zago e Mello (2014) - desempenho. Portanto, esses resultados conduzem a não rejeição da hipótese $\mathbf{H}_{1}$, havendo evidências que levam à rejeição das demais hipóteses levantadas.

Deve-se destacar que a análise conjunta do poder explicativo do modelo e das variáveis investigadas mostrou que alguns fatores podem não possuir valor preditivo relevante. Isso pode sugerir particularidades, do mercado de capitais brasileiro ou do grupo das maiores firmas, no que tange a qualidade da estrutura de governança corporativa. Nesse sentido, o $\mathrm{R}^{2}$ de $21,5 \%$ aponta que existem variáveis endógenas e exógenas às firmas que não foram contempladas na pesquisa, dando direção para a busca de evidências futuras.

A inexistência de influência da emissão de ADR sobre a qualidade da governança pode ser justificada pela baixa quantidade de empresas da amostra emitem ADR (22\%) e isso talvez guarde relação com os custos atrelados às exigências do mercado norte-americano. Também foi observado que uma maior proporção do capital de terceiros não impulsiona as empresas a aprimorar a governança corporativa. Nesse caso o endividamento pode surgir como limitador, já que a menor disponibilidade de recursos compete com os custos elevados de controle.

O tamanho é apontado na literatura como variável explicativa da governança, mas nesta pesquisa o porte não se mostrou influente, talvez por se tratar de um grupo economicamente representativo e homogêneo. Conclusão semelhante é feita acerca do valor e do desempenho, porque oportunidade de crescimento e performance econômica também não são determinantes da qualidade da governança corporativa. Os resultados descritos podem sinalizar aos gestores como o perfil da firma se relaciona com suas características de governança e auxiliar gestores a traçar estratégias visando aprimoramento dos controles.

O segundo objetivo específico da pesquisa foi atingido mediante a análise de correlação da governança em cada dimensão com os aspectos investigados, evidenciada na Tabela 9.

Tabela 9 - Análise de correlação: dimensões da governança e fatores determinantes

\begin{tabular}{rrrrrrr}
\hline Variáveis & Ngov & ADR & End & Tam & Qtobin & ROA \\
\hline Dimensão 1 & 0,339 & $-0,127$ & $-0,201$ & $-0,147$ & $-0,001$ & 0,165 \\
Sig. (2 caudas) & $0,002^{\star \star \star}$ & 0,258 & $0,072^{\star}$ & 0,189 & 0,993 & 0,141 \\
Dimensão 2 & 0,071 & 0,396 & $-0,035$ & 0,363 & 0,086 & $-0,033$ \\
Sig. (2 caudas) & 0,532 & $0,000^{\star \star \star}$ & 0,755 & $0,001^{\star \star \star}$ & 0,444 & 0,767 \\
Dimensão 3 & 0,341 & 0,233 & 0,130 & 0,179 & 0,031 & $-0,040$ \\
Sig. (2 caudas) & $0,002^{\star \star \star}$ & $0,036^{\star \star}$ & 0,247 & 0,110 & 0,785 & 0,723 \\
Dimensão 4 & 0,139 & $-0,034$ & 0,034 & $-0,082$ & 0,305 & 0,098 \\
Sig. (2 caudas) & 0,217 & 0,764 & 0,385 & 0,465 & $0,006^{\star \star \star}$ & 8,76 \\
Observações & 81 & 81 & 81 & 81 & 81 & 81 \\
\hline
\end{tabular}

Nota. ${ }^{* * *}$ significante ao nível de $1 \%$; ** significante ao nível de $5 \%$; ${ }^{*}$ significante ao nível de $10 \%$.

Fonte: dados da pesquisa. 
Conforme a Tabela 9, a dimensão relativa à estrutura de propriedade e controle mostrou correlação estatisticamente significativa e positiva com a participação nos níveis diferenciados de governança corporativa (Sig. < 1\%). Assim, firmas com menor concentração acionária e mais ações ordinárias participam dos melhores segmentos de listagem da B3, provavelmente em razão das exigências da bolsa de valores. Essa dimensão teve correlação estatisticamente significativa e negativa com o endividamento ao nível de $10 \%$. Portanto, empresas com maior concentração de voto e mais acionistas preferenciais são mais endividadas.

A dimensão que representa a auditoria e conselho fiscal mostrou correlação significante ao nível de 1\% com a emissão de ADR e também com o tamanho da empresa. Isso é justificável na medida que o mercado norte-americano deve ser exigente com a estruturação desses mecanismos de controle e monitoramento. Para tanto, empresas maiores devem possuir mais recursos para estruturação e custeio da auditoria e do conselho fiscal, mesmo que apenas 33\% das firmas tenham esse último órgão fiscalizador.

Aspectos institucionais externos na forma de imperativos das bolsas de valores brasileira e estadunidense apresentaram relação estatisticamente significante e positiva com (1\% e 5\%) a dimensão conselho de administração e outros comitês. A dimensão de relacionamento com investidores mostrou correlação positiva, estatisticamente significante ao nível de $1 \%$, com o valor das firmas. Esses resultados retratam como a proximidade da empresa com o stakeholder pode interferir na precificação no mercado de capitais.

\section{CONCLUSÃO}

Este estudo buscou caracterizar a governança corporativa sob caráter multidimensional em um grupo de empresas economicamente representativas no mercado de capitais brasileiro. Adicionalmente, verificou-se como alguns aspectos, exógenos e endógenos, relacionavam-se com a qualidade da governança corporativa. Os resultados mostram uma considerável adesão aos doze componentes investigados. Havia expectativa de melhores perfis corporativos de governança por serem firmas com situação econômica representativa. Contudo, o cenário demonstrado pode sugerir que esse não é um fator distintivo da governança corporativa.

Observou-se ainda que, enquanto alguns aspectos são valorizados nas empresas, como o poder de voto do acionista, a atuação da auditoria, a não centralização dos interesses do gestor e a aproximação entre investidor e empresa; outros nem tanto, caso da dispersão do controle, a fiscalização em caráter permanente da gestão, a política de incentivos e a independência da gestão. Entre as dimensões investigadas no estudo, destacaram-se aquelas alusivas à auditoria e ao relacionamento com investidores. Isso pode indicar que as firmas estão mais preocupadas em sinalizar a stakeholders confiabilidade das informações contábil-financeiras e em construir uma boa imagem perante o mercado.

$\mathrm{Na}$ análise acerca dos determinantes da governança, evidenciou-se que a participação nos níveis diferenciados da bolsa de valores afeta positivamente a qualidade dos mecanismos de alinhamento de interesse entre agentes e proprietários. Os demais aspectos não explicam a governança corporativa adotada pelas empresas objeto de estudo. Por outro lado, notou-se que o condicionamento da firma aos regulamentos de governança emanados pelos mercados interno e externo, além do porte e do endividamento, podem explicar o desenvolvimento da governança no que se refere às dimensões de estrutura de propriedade e auditoria. A regulação de mercados e o valor das empresas contribui para justificar como a governança corporativa é aprimorada nos aspectos gestão e o relacionamento da firma com seus investidores.

A pesquisa, ao analisar a governança corporativa das firmas por dimensão, permite uma compreensão minuciosa de seus aspectos específicos no contexto brasileiro. Essa contribuição é importante para o futuro do campo de estudo contábil que abrange o monitoramento da gestão e suas implicações. O que se observa é a maior parte dos estudos preocupados com a agregação de diferentes aspectos para compor índices abrangentes, limitação das pesquisas.

Sob a perspectiva da prática gerencial-contábil, a abordagem possibilita a identificação de gaps no que se refere à utilização de mecanismos de governança corporativa mais eficientes ou mais aderentes. Em suma, a pesquisa colabora para a visualização de áreas da governança que são priorizadas ou preteridas pelas firmas. Assim são fomentadas discussões acadêmicas e gerenciais acerca dos mecanismos que são e/ou deveriam ser empregados nas firmas.

Os achados ajudam a mitigar deficiências na qualidade da governança corporativa das empresas, levantando questões subjacentes ao problema de pesquisa como (i) preferências entre instrumentos de controle e monitoramento da gestão; (ii) custos de agência e recursos para que a governança seja estruturada; (iii) características específicas endógenas e exógenas do mercado e das firmas capazes de influenciar a governança. Com isso são fornecidos insights para que as empresas promovam instrumentos de governança a partir das dimensões mais relevantes. Essa discussão é pertinente porque apenas a participação nos níveis diferenciados se mostrou capaz de influenciar a variável de interesse.

Em síntese, a pesquisa contribui ampliando o debate sobre a utilização da governança corporativa pela firma como instrumento potencial agregador de vantagens financeiras e não financeiras, uma vez que ela resguarda os interesses dos proprietários, mitigando custos derivados da expropriação, de desvios de interesses e de má conduta. Adicionalmente, a pesquisa ajuda na identificação de dimensões da governança corporativa priorizadas pelas empresas, inclusive possíveis variáveis, internas e externas, que explicariam essa priorização.

Às pesquisas futuras, sugere-se comparação entre firmas de menor representatividade econômica, contrapondo perfis e apontando similaridades e diferenças. Os estudos posteriores também podem explorar diferenças entre as práticas de governança corporativa, por dimensão, levando-se em conta a entrada nos níveis diferenciados da B3. Sugere-se ainda a ampliação do período de análise afim de gerar evidências do comportamento da governança corporativa ao longo do tempo nas empresas. 


\section{Referências}

AKERLOF, G. A. The market for "lemons": quality uncertainty and market mechanism. The Quarterly Journal of Economics, v. 84, n. 3, p. 488-500, 1970.

ALMEIDA, M. A.; SANTOS, J. F.; FERREIRA, L. F. V. M.; TORRES, F. J. V. Determinantes da qualidade das práticas de governança corporativa das empresas brasileiras de capital aberto que possuem investimentos públicos. Revista Brasileira de Gestão de Negócios, v. 12, n. 37, p. 369-387, 2010.

ARAÚJO, J. G.; CONFESSOR, K. L. A.; SANTOS, J. F.; OLIVEIRA, M. R. G.; PRAZERES, R. V. A estrutura de capital e a governança: análise dos conselhos de administração e estrutura de propriedade nas empresas listadas no IBRX-100. Gestão, Finanças e Contabilidade, v. 7, n. 2, p. 121-140, 2017.

BARROS, C. M. E.; SILVA, P. Y. C.; VOESE, S. B. Relação entre o custo da dívida de financiamentos e governança corporativa no Brasil. Contabilidade, Gestão e Governança, v. 18, n. 2, 07-26, 2015.

BRANDÃO, I. F.; CRISÓSOMO, V. L. Concentração de propriedade e qualidade da governança da empresa brasileira. Revista Brasileira de Finanças, v. 13, n. 3, p. 438-469, 2015.

BRANDÃO, I. F.; MOTA, A. F; VASCONCELOS, A. C.; DE LUCA, M. M. M. Internacionalização e governança nas maiores companhias abertas do Brasil. Revista Gestão Organizacional, v. 7, n. 3, p. 19-32, 2014

BEUREN, I. M.; SILVA, J. O. Evidenciação da remuneração variável dos executivos nas maiores empresas brasileiras listadas na BM\&FBovespa. Enfoque: Reflexão Contábil, v. 34, n. 3, p. 95-124, 2015.

CARDOSO, V. I. C.; DE LUCA, M. M. M.; ALMEIDA, T. A. Práticas de disclosure econômico e socioambientais nas maiores empresas do Brasil. Revista de Administração da UFSM, v. 9, n. 1, p. 156-173, 2016.

CHUNG, K. H.; PRUITT, S. W. A Simple approximation of Tobin's q. Financial Management, v. 23, n. 3, p. 70-74, 1994.

COLLIS, J.; HUSSEY, R. Pesquisa em administração: um guia prático para alunos de graduação e pós-graduação. 2 ed. Porto Alegre: Bookman, 2005.

CUNHA, P. R.; POLITELO, L. Determinantes do nível de governança corporativa das empresas brasileiras de capital aberto do setor de consumo cíclico da BM\&FBovespa. Advances in Scientific and Applied Accounting, v. 6, n. 2, p. 211-335, 2013.

FONSECA, C. V. C.; SILVEIRA, R. L. F.; HIRATUKA, C. A relação entre a governança corporativa e a estrutura de capital de empresas brasileiras no período 2000-2013. Enfoque: Reflexão Contábil, v. 35, n. 2, p. 35-52, 2016.

JENSEN, M. C.; MECKLING, W. H. Theory of the firm: managerial behavior, agency costs and ownership structure. Journal of Financial Economics, v. 3, n. 4, p. 305-360.

KAYO, E. K.; TEH, C. C.; BASSO, L. F. C. Ativos intangíveis e estrutura de capital: a influência das marcas e patentes sobre o endividamento. Revista de Administração, v. 41, n. 2, p. 158-168, 2006

KLANN, R. C.; KREUZBERG, F; BECK, F. Fatores de risco evidenciados pelas maiores empresas listadas na BM\&FBovespa. Revista de Gestão Ambiental e Sustentabilidade, v. 3, n. 3, p. 78-89, 2014.

KLAPPER, L. F.; LOVE, I. Corporate governance, investor protection, and performance in emerging markets. Journal of Corporate Finance, v. 10, n. 5, p. 703-728, 2004.

LAMEIRA, V. J.; NESS JR., W. L. Os determinantes da qualidade da governança praticada pelas companhias abertas brasileiras. Revista de Negócios, v. 16, n. 3, p. 33-52, 2011.

LAMEIRA, V. J.; NESS JR., W. L.; MACEDO-SOARES, T. D. A. Governança corporativa: impactos no valor das companhias abertas brasileiras. Revista de Administração da USP, v. 42, n. 1, p. 64-73, 2007.

LOPES, A. B. A teoria dos contratos, governança corporativa e contabilidade. In: LOPES, A. B.; IUDÍCIBUS, S. (Coord.). Teoria avançada da contabilidade. 2 ed. São Paulo: Atlas, 2012. p. 173-187.

MAIA, A. B. G. R.; VASCONCELOS, A. C.; DE LUCA, M. M. M. Governança corporativa e internacionalização do capital social das companhias do setor de construção e transportes. Revista Eletrônica de Negócios Internacionais, v. 8, n. 2, p. 40-60, 2013.

MAPURUNGA, P. V. R.; PONTE, V. M. R.; OLIVEIRA, M. C. Determinantes das práticas de governança corporativa: um estudo nas empresas registradas na CVM. Advances in Scientific and Applied Accounting, v. 8, n. 3, p. 374-395, 2015.

MYERS, S. C.; MAJLUF, N. S. Corporate financing and investment decisions when firms have information that investors do not have. Journal of Financial Economics, v. 13, p. 187-221, 1984

OLIVA, E. C.; ODDONE, G.; ALBUQUERQUE, L. G. Práticas e tendências em governança corporativa. In: LAMENZA, A. (Org.). Estratégias empresariais: pesquisas e casos brasileiros. São Paulo: Saint Paul, 2008

RIPAMONTI, A.; KAYO, E. K. Corporate governance and capital structure in Brazil: stock, bonds and substitution. Revista de

Administração Mackenzie, v. 17, n. 5, p. 85-109, 2016.

SANTOS, J. G. C.; VASCONCELOS, A. C.; LUCA, M. M. M. Internacionalização de empresas e governança corporativa: uma análise das maiores companhias abertas do brasil. Advances in Scientific and Applied Accounting, v. 8, n. 3, p.300-319 2015.

SILVEIRA, A. D. M.; BARROS, L. A. B. C. Determinantes da qualidade da governança corporativa das companhias abertas brasileiras. Revista de Administração da USP, v. 14, n. 3, p. 1-29, 2008.

SILVEIRA, A. D. M.; LEAL, R. C. P.; BARROS, L. A. B. C.; CARVALHAL-DA-SILVA, A. L. Evolution and determinants of firm-level corporate governance quality in Brazil. Revista de Administração da USP, v. 44, n. 3, 173-189, 2009.

SOUZA, F. C.; MURCIA, F. D-R.; MARCON, R. Bonding hypothesis: análise da relação entre disclosure, governança corporativa e internacionalização de companhias abertas no Brasil. Contabilidade, Gestão e Governança, v. 14, n. 2, p. 62-81, 2011.

SUNDER, S. Teoria da contabilidade e do controle. São Paulo: Atlas, 2014.

TERRA, P. R. S.; LIMA, J. B. N. Governança corporativa e a reação do mercado de capitais à divulgação das informações contábeis. Revista Contabilidade e Finanças, n. 42, p. 35-49, 2006.

VIEIRA, K. M.; VELASQUEZ, M. D. P.; LOSEKANN, V. L.; CERETTA, P. S. A influência da governança corporativa no desempenho e na estrutura de capital das empresas listadas na Bovespa. Revista Universo Contábil, v. 7, n. 1, 49-67, 2011.

ZAGO, C.; MELLO, G. R. Determinantes da qualidade da governança corporativa eletrônica. Revista Gestão.Org, v. 12, n. 2, p. 125-133, 2014. 